\title{
THE LOW-ENERGY ISOBAR SEPARATOR FOR ANIONS: PROGRESS REPORT
}

\author{
W E Kieser ${ }^{1,2,3} \bullet$ John Eliades $^{1} \bullet$ A E Litherland ${ }^{1} \cdot$ Xiaolei Zhao $^{1,2} \cdot$ Lisa Cousins $^{4} \bullet \mathrm{S} \mathrm{J} \mathrm{Ye}^{4}$
}

\begin{abstract}
The suppression of interferences from atomic and molecular isobars is a key requirement for the extension of accelerator mass spectrometry (AMS) to the analysis of new cosmogenic isotopes and for increasing the range of applications for small AMS systems. In earlier work, it was shown that unwanted isobars can be eliminated by anion-gas reactions (Litherland et al. 2007). Recently, a prototype system in which such reactions could be applied to ions from an AMS ion source, the Isobar Separator for Anions (ISA), was described (Eliades et al. 2009). This system decelerates the beam of rare anions from $\mathrm{keV}$ to $\mathrm{eV}$ energies, guides them through a single radiofrequency quadrupole (RFQ) gas cell, and re-accelerates them for further analysis in a 2.5MV AMS system. Tests of this system with $\mathrm{Cl}$ and $\mathrm{S}$ anions and $\mathrm{NO}_{2}$ gas showed a suppression of $\mathrm{S}$ with respect to $\mathrm{Cl}$ of over 6 orders of magnitude, with a transmission of $\sim 30 \%$ for the $\mathrm{Cl}$ beam. In this work, results of the analysis of a range of standard reference materials are reported; these show the linearity of the system for measuring the ${ }^{36} \mathrm{Cl} /{ }^{35} \mathrm{Cl}$ ratio over a span of 2 orders of magnitude. Further tests, using the AMS system as a diagnostic tool, have provided clues about the loss of $\mathrm{Cl}$ at higher cell pressure and the nature of the residual low level of $\mathrm{S}$ transmission. These lead to the assessment of various gases for cooling the $\mathrm{Cl}^{-}$beam. Suppression measurements for ${ }^{41} \mathrm{~K}$ in the analysis of ${ }^{41} \mathrm{Ca}$, using $\mathrm{NO}_{2}$ as a reaction gas, are also discussed. These preliminary measurements have provided data for the development of a more advanced system with separate cooling and reaction cells.
\end{abstract}

\section{INTRODUCTION}

The very high sensitivity of accelerator mass spectrometry (AMS) for measuring rare isotopes depends on its ability to eliminate or significantly suppress both atomic and molecular isobars of the atom of interest. While the destruction of molecular isobars is usually accomplished by charge changing in the stripper gas in the terminal of tandem accelerators or following acceleration in single-stage accelerators, the removal of atomic isobars, aside from the well-known cases where they do not form negative ions, is more complicated. Techniques used to date include the use of foils to separate the isobars by range or rate of energy loss (Raisbeck et al. 1994), the use of gas-filled magnets (Paul 1990), and even complete stripping of the ions (Galindo-Uribarri et al. 2007). In the case of isotopes such as ${ }^{36} \mathrm{Cl}$ and ${ }^{41} \mathrm{Ca}$, the effective use of these techniques requires higher energies and therefore larger accelerators.

Litherland et al. (2007) discussed the use of selective anion-gas reactions to eliminate unwanted isobars and proposed the use of a gas cell containing a radiofrequency quadrupole (RFQ) to control the effects of scattering for low-energy ions. In the same paper, they reported earlier work (Dunkin et al. 1972) on the destruction of $\mathrm{S}^{-}$ion in $\mathrm{NO}_{2}$ gas and the transmission of $\mathrm{Cl}^{-}$through the same medium, along with a contemporary confirmation of this effect (Doupé 2004).

The Isobar Separator for Anions (ISA), a prototype device incorporating the ideas set forth in (Litherland et al. 2007), with a single RFQ reaction cell, has been built at the IsoTrace Laboratory. Its construction and the initial tests of its use to attenuate $\mathrm{S}^{-}$in the presence of $\mathrm{Cl}^{-}$have been described by Eliades et al. (2009). The reader is referred to this paper for the full details of the operation of the ISA, but an extended summary of these is presented here. Figure 1 shows a schematic with details of the active elements of the ISA itself. Negative ions are generated in an 860 type Cs sputter source (anion energy $\sim 20 \mathrm{keV}$ ), mass analyzed in a $90^{\circ}$ magnet, collimated to $\pm 10 \mathrm{mr}$, and then retarded to

\footnotetext{
${ }^{11}$ IsoTrace Laboratory, University of Toronto, 60 Saint George St., Toronto, Ontario M5S 1A7, Canada.

${ }^{2}$ Current affiliation: Department of Physics, University of Ottawa, 150 Louis Pasteur, Ottawa, Ontario K1N 6N5 Canada.

${ }^{3}$ Corresponding author. Email: liam.kieser@utoronto.ca.

${ }^{4}$ Ionics Mass Spectrometry Group, 32 Nixon Road, Unit 1, Bolton, Ontario L7E 1W2, Canada.
}

C 2010 by the Arizona Board of Regents on behalf of the University of Arizona

Proceedings of the 20th International Radiocarbon Conference, edited by A J T Jull

RADIOCARBON, Vol 52, Nr 2-3, 2010, p 236-242 
an energy of several tens of $\mathrm{eV}$ in a series of electric lenses. Further retardation is accomplished using 2 sections of RFQs, after which the ions are introduced into the windowless gas cell containing both an RFQ and a set of 4 tapered gradient electrodes. The latter electrodes produce a small axial field $(\leq 10 \mathrm{mV} / \mathrm{cm})$, which serves to maintain a minimum drift velocity of the ions through the cell. Following the cell, the ions are re-accelerated to their original ion source energy and are analyzed using the tandem accelerator and the IsoTrace Heavy Element analysis line (Kilius et al. 1990).

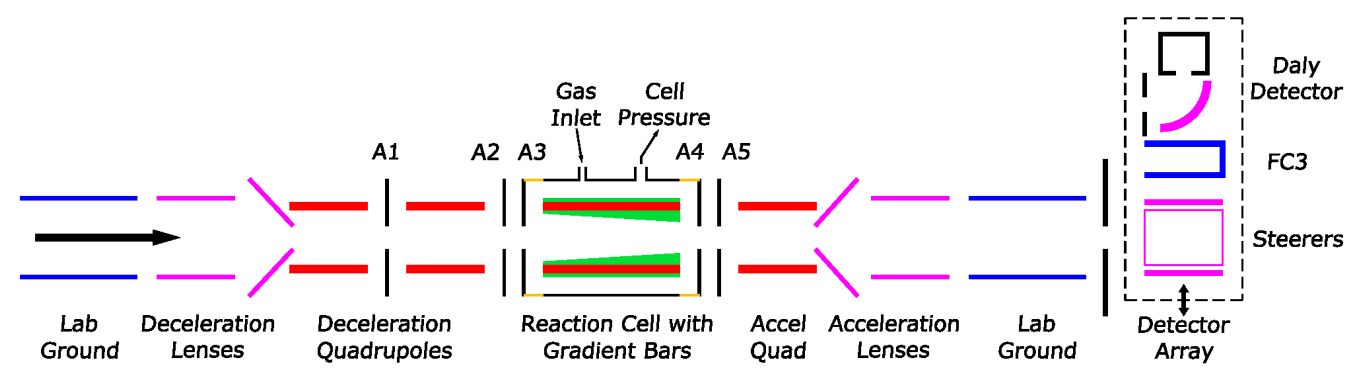

Figure 1 Schematic diagram of the active elements of the ISA column. The labels A1-A5 designate apertures on each of which the voltage can be adjusted from 0-240 V. The beam of rare isotopes, mass selected by a magnet, enters from the left and is decelerated in the first 2 electrodes and initial quadrupole to an energy of $<100 \mathrm{eV}$. Further energy reduction is provided by the next quadrupole so that the ions are introduced into the cell with an energy $<10 \mathrm{eV}$. After traversing the cell, the ions are re-accelerated to their original energy (from the ion source) and are injected into the accelerator. The detector array provides optional particle detection capability for offline measurements. In this work, the reaction cell also provided a cooling function. For a detailed description, see Eliades et al. (2009).

In this paper, further developments in the analysis of ${ }^{36} \mathrm{Cl}$ are described and the results of an investigation of the use of the ISA for the analysis of ${ }^{41} \mathrm{Ca}$ will be discussed.

\section{MEASUREMENT DETAILS}

The ISA is designed to transmit only the beam of rare isotopes (mass 36 in the case of $\mathrm{Cl}$ analysis); the abundant isotopes (masses 35 and 37) are measured in off-axis Faraday cups following the massanalyzing magnet. However, to accelerate the process of testing the effects of varying gas pressures and other ISA parameters (reported in Eliades et al. 2009), nanoampere beams of the abundant species were generated by throttling back the ion source. Similar ion source and ISA settings were used with the mass 36 beam for the measurements of the 4 reference material targets described below, as it was not worthwhile to change the ion source setup for such a short measurement. In addition, the coupling between the ISA and the rest of the AMS system (through the $0^{\circ}$ port of the inflection magnet used for ${ }^{14} \mathrm{C}$ and ${ }^{129} \mathrm{I}$ analyses) was ion optically quite inefficient, reducing the transmission by a factor of $\sim 5$. An additional lens has now been designed to remove this obstacle.

For the measurements described in this paper, most of the ISA parameters were unchanged from those given in Table 1 of Eliades et al. (2009). The principal modification was the diameter of the apertures surrounding the reaction cell (A2, A3, A4, and A5 in Figure 1), which were all $3 \mathrm{~mm}$. Minor tuning adjustments of the rod offset and aperture voltages were within the ranges reported in Eliades et al. (2009). The pressure of the gas in the cell was measured by a capacitance manometer (MKS model 626A) connected directly to the cell by a tube (6 $\mathrm{mm}$ inside diameter).

\section{${ }^{36} \mathrm{Cl}$ Reference Material Measurements}

A set of four ${ }^{36} \mathrm{Cl}$ reference materials in the form of $\mathrm{AgCl}$ were obtained from Prof Marc Caffee at PRIME Lab. Aliquots of each of these were mixed with $\mathrm{Nb}$ in a volume ratio of 1 part $\mathrm{AgCl}$ to 2 
parts $\mathrm{Nb}$ and pressed into aluminum target holders. For each target, the current of ${ }^{35} \mathrm{Cl}^{-}$(typically $200 \mathrm{nA}$ ) was monitored in a movable Faraday cup on the focal plane of the magnet before the ISA and the mass 36 beam was guided through the ISA, through the tandem accelerator and the heavy element line to the gas ionization detector where the total energy of the ions was measured. The pressure of $\mathrm{NO}_{2}$ in the reaction cell for these measurements was $10.5 \mu \mathrm{bar}$.

The results from the 4 reference material targets are given in Table 1. Each measured number is the weighted average of 12 separate runs of $300 \mathrm{~s}$ each for targets A and B, $600 \mathrm{~s}$ for target C, and $900 \mathrm{~s}$ for target D. A plot of the measured data versus the PRIME Lab values is shown in Figure 2 with a linear fit through the points for which the slope is $1.030 \pm 0.013$, and $R=0.999$.

Table $1{ }^{36} \mathrm{Cl} /{ }^{35} \mathrm{Cl}$ ratios for the reference materials obtained from PRIME Lab, Purdue University. The ISA measured values are normalized to the PRIME Lab reference value for target A.

\begin{tabular}{lll}
\hline Target ID & PRIME Lab reference value & ISA measured value \\
\hline A & $4.18 \times 10^{-11}$ & $(4.18 \pm 0.09) \times 10^{-11}$ \\
B & $4.42 \times 10^{-12}$ & $(3.94 \pm 0.20) \times 10^{-12}$ \\
C & $1.02 \times 10^{-12}$ & $(8.72 \pm 0.80) \times 10^{-13}$ \\
D & $4.08 \times 10^{-13}$ & $(3.82 \pm 0.30) \times 10^{-13}$ \\
\hline
\end{tabular}

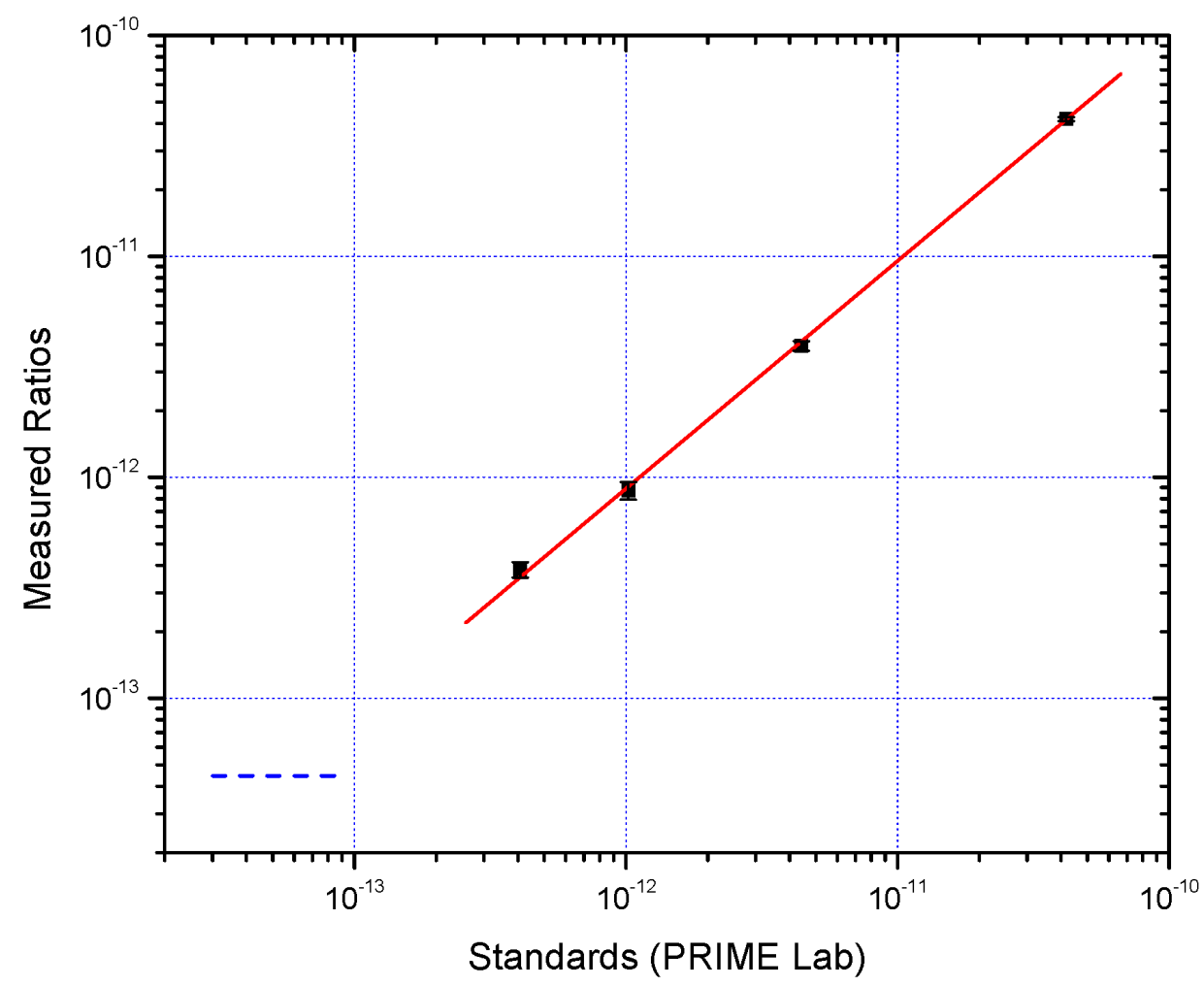

Figure 2 Measured ${ }^{36} \mathrm{Cl} / \mathrm{Cl}$ ratios for the four ${ }^{36} \mathrm{Cl}$ reference materials obtained from the PRIME Lab versus the accepted values of these reference materials. Measured values were normalized to the reference values at the uppermost point. The line through the data points is a least-squares fit for which the slope is $1.030 \pm 0.013$ and $R=0.999$. The dashed line at the low end of the plot is an estimate of the level of ${ }^{36} \mathrm{~S}$ leaking through the ISA calculated from the attenuation measurements reported in Eliades et al. (2009). 


\section{The Cooling of $\mathrm{Cl}^{-}$lons in Various Gases}

The ions generated in a sputter source leave the source with a distribution in momentum in the 3 spatial dimensions and in energy centered at the principal energy provided by the overall acceleration of the source (Kilius et al. 1984, 1987). Because this energy spread $(\sim 50 \mathrm{eV})$ is small relative to the overall energy of the ion, it is of little significance for normal AMS operations. However, in the ISA, where the energy of all the transmitted ions is reduced to $\sim 10 \mathrm{eV}$, this means that a significant number of ions could enter the cell with energies $>60 \mathrm{eV}$, well above the center-of-mass energy threshold for reactions in the gas cell, which could destroy the ion of interest. If a cell containing a non-reactive gas were placed ahead of the reaction cell in the beam path, the anions, while still under the control of the average field of the RFQ, scatter from the gas atoms or molecules, lose energy (i.e. are cooled), and are returned to the axis of the RFQ through the influence of the transverse RF field. The anions then emerge from the cell with a uniform energy and reduced emittance. This cooling process is described in more detail by Tanner et al. (2002).

A problematic feature of the plots of transmission versus gas pressure (e.g. Figure 2 of Eliades et al. 2009 ) is the rapid drop of the $\mathrm{Cl}^{-}$transmission to $\sim 50 \%$ with only $1 \mu$ bar of $\mathrm{NO}_{2}$ in the reaction cell and the steady, although not as steep, increase in this attenuation to $\sim 70 \%$ at a cell pressure of $12 \mu$ bar. One possible cause of this loss may be the use of 1 gas cell, with one or several gases, for both cooling the ions as well as for the isobar selection reaction. The energy dependence for the destruction of $\mathrm{Cl}^{-}$by reactions and charge changing in $\mathrm{NO}_{2}$ (shown in Figure 1 of Litherland et al. 2007) indicates the onset of a destruction process at $\sim 5 \mathrm{eV}$ in the laboratory frame of reference. Thus, given the energy distribution of anions from a sputter source described above, it is essential to cool the $\mathrm{Cl}^{-}$in a non-reactive gas before admitting it to the reaction cell containing $\mathrm{NO}_{2}$.

The search for an appropriate cooling gas was somewhat constrained by the use of cryopumps as the only vacuum pumping on the main vacuum enclosure of the ISA. One would expect that cooling with $\mathrm{He}$ would result in the lowest losses; however, with the pumping rates involved, $\mathrm{He}$ and $\mathrm{Ne}$ could not be used in any sustained fashion on this system. The data in Figure 3 for $\mathrm{Cl}^{-}$in $\mathrm{Ar} \mathrm{NO}_{2}$, $\mathrm{N}_{2}$, and $\mathrm{CH}_{4}$ were obtained using a $5-\mathrm{nA}$ beam of ${ }^{37} \mathrm{Cl}^{-}$with the transmitted beam accelerated through the tandem and collected in the Faraday cup in front of the gas ionization detector.

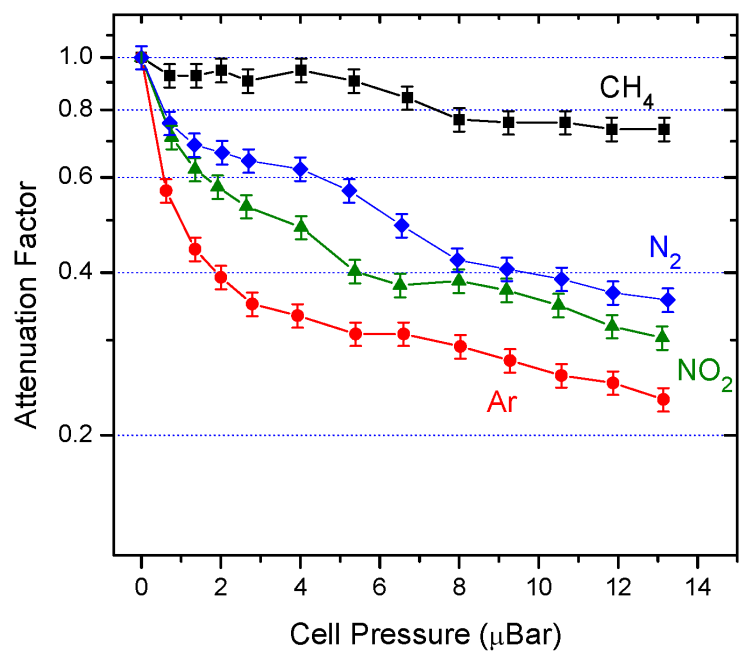

Figure 3 Plot of the attenuation of $\mathrm{Cl}^{-}$ions as a function of the pressure of various gases in the reaction cell, used in this case to test the cooling properties of these gases. 


\section{ISA Measurements of the Ca-K System}

Another intermediate mass isotope that is difficult to analyze using small AMS systems is ${ }^{41} \mathrm{Ca}$, for which the interfering isobar is ${ }^{41} \mathrm{~K}$. As $\mathrm{Ca}$ does not form anions easily, $\mathrm{CaH}_{3}{ }^{-}$or $\mathrm{CaF}_{3}{ }^{-}$are conventionally used (Elmore et al. 1990; Freeman et al. 1995). Initial work on this system using fluoride molecular ions from the ion source and the ISA with argon gas for collision induced destruction was reported by Zhao et al. (2009). They found that the destruction of the $\mathrm{KF}_{3}{ }^{-}$ions was $\sim 1000$ times that of the $\mathrm{CaF}_{3}{ }^{-}$ions, but the loss of the $\mathrm{CaF}_{3}{ }^{-}$ions was $\sim 85 \%$.

To determine whether the relative destruction of the $\mathrm{K}$ and the transmission of the $\mathrm{Ca}$ might be improved by using a reactive rather than an inert gas, the $\mathrm{CaF}_{3}{ }^{-}$and $\mathrm{KF}_{3}{ }^{-}$measurements were repeated using $\mathrm{NO}_{2}$ in the reaction cell. A target of $\mathrm{PbF}_{2}$ was used, with sufficient $\mathrm{Ca}$ and $\mathrm{K}$ well mixed into the $\mathrm{PbF}_{2}$ before pressing to produce several $\mathrm{nA}$ of ${ }^{40} \mathrm{CaF}_{3}{ }^{-}$and $\sim 50,000$ events $/ \mathrm{s}$ of ${ }^{39} \mathrm{~K}^{+2}$ from ${ }^{39} \mathrm{KF}_{3}{ }^{-}$in the gas ionization detector. From the ISA, these ions were transmitted through the accelerator and the resulting ${ }^{39} \mathrm{~K}^{2+}$ and ${ }^{40} \mathrm{Ca}^{2+}$ ions were counted in the gas ionization detector and the Faraday cup before it, respectively. The resulting attenuation curves are shown in Figure 4. Note that the formation of $\mathrm{KF}_{3}{ }^{-}$in the ion source is suppressed by a factor of only $\sim 1000$ with respect to $\mathrm{CaF}_{3}{ }^{-}$. Also shown in Figure 4, as a demonstration of a highly effective destruction cross-section are the results for ${ }^{39} \mathrm{~K}^{-}$atomic ions in $\mathrm{NO}_{2}$, with the resulting ${ }^{39} \mathrm{~K}^{3+}$ ions counted in the gas ionization detector.

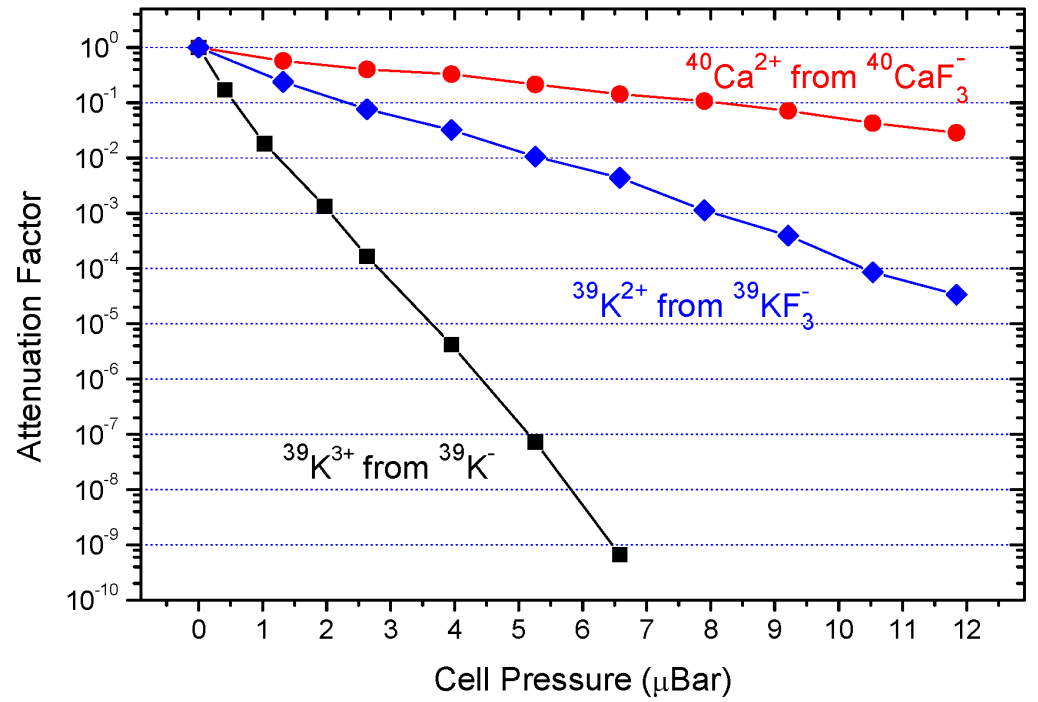

Figure 4 Attenuation curves for ${ }^{40} \mathrm{CaF}_{3}{ }^{-}$and ${ }^{39} \mathrm{KF}_{3}-$ ions, using $\mathrm{NO}_{2}$ gas in the ISA reaction cell. Also shown, for comparison, is the attenuation of the ${ }^{39} \mathrm{~K}^{-}$in the $\mathrm{NO}_{2}$ gas.

\section{DISCUSSION}

The ${ }^{36} \mathrm{Cl}$ reference material measurements demonstrate that the ISA technique is indeed scalable over 2 orders of magnitude in ion intensity and thus shows promise for routine analytical work. However, as indicated by the statistics in these measurements, further work has to be done on the transmission efficiency of the overall system. Part of this inefficiency is due to the poor ion optical match between the ISA system and the injection line of the AMS system discussed above. 
The attenuations measured in the cooling experiments appear to vary with the mass of the cooling gas molecule or atom. An exception to this trend is the Ar curve, which, as a monatomic gas is involved in the collisions, may result in a harder impact collision than in the case of a molecule of equivalent mass in which lower-energy internal degrees of freedom may make more inelastic collisions available. As indicated above, the $\mathrm{Cl}^{-}$losses, which appear to be the result of the $\mathrm{Cl}^{-}$entering the reaction cell with too broad a range of energies, could be mitigated by the addition of a second cell for cooling the ions. This will reduce the number of ions that have energy greater than the onset of the destruction of $\mathrm{Cl}^{-}$in $\mathrm{NO}_{2}$, before they enter the reaction cell. Components for a second cell have been manufactured and its assembly and installation will follow shortly.

The measurements on the $\mathrm{CaF}_{3}{ }^{-}$and $\mathrm{KF}_{3}{ }^{-}$ions in $\mathrm{NO}_{2}$ show the effectiveness of $\mathrm{NO}_{2}$ as a reaction gas, as the destruction of the $\mathrm{KF}_{3}{ }^{-}$is greater in $\mathrm{NO}_{2}$ than in $\mathrm{Ar}\left(3.4 \times 10^{-5}\right.$ compared with $\left.10^{-3}\right)$. However, the attenuation loss of the $\mathrm{CaF}_{3}^{-}$is even greater in $\mathrm{NO}_{2}$ than in $\mathrm{Ar}(97 \%$ compared with $85 \%$ ). Thus, the relative attenuation is slightly less for the $\mathrm{NO}_{2}$ and, as the transmission of the $\mathrm{CaF}_{3}{ }^{-}$ in $\mathrm{NO}_{2}$ is a factor 5 lower, the use of this reactive gas does not provide any improvement over the collision induced destruction using Ar gas, unless a solution can be found for the $\mathrm{CaF}_{3}{ }^{-}$losses (e.g. precooling in another gas). In both the $\mathrm{NO}_{2}$ and the Ar measurements, $\mathrm{KF}_{3}{ }^{-}$is more rugged than expected, given that it has 1 more $\mathrm{F}$ atom than the superhalogen anion for this compound. This is consistent with the ruggedness of $\mathrm{SiF}_{6}{ }^{-}$, another case of the anion with 1 more $\mathrm{F}$ than the superhalogen anion, in the calculation by Gutsev (1993). As the $\mathrm{KF}_{3}{ }^{-}$has both a more weakly bound electron and fluorine atom, it should be possible to find a different collision gas that will destroy the $\mathrm{KF}_{3}{ }^{-}$ more effectively and have a lesser effect on the $\mathrm{CaF}_{3}{ }^{-}$. This work will be revisited when an additional cell for cooling is available.

\section{CONCLUSION}

In its present form, with attenuations of $>10^{6}$ for ${ }^{36} \mathrm{~S}^{-}$in $\mathrm{NO}_{2}$ and $10^{3}$ for $\mathrm{KF}_{3}{ }^{-}$in $\mathrm{Ar}$, the Isobar Separator shows considerable promise for enhancing these measurements on most AMS systems. Future work, using an independent cooling cell and refining the selection of cooling and reaction gases, is expected to increase this potential considerably. Finally, with the ability of the reaction cell system to break up molecular isobars, the function (and hence terminal voltage) of the accelerator required for work with the Isobar Separator may well be reduced to providing sufficient energy for low dark noise operation of the final ion detector.

\section{ACKNOWLEDGMENTS}

The financial support from Major Resources Support, the Idea to Innovation and Discovery Grant programs of the Canadian Natural Sciences, and Engineering Research Council are gratefully acknowledged. XLZ would also like to acknowledge the financial support from Xi'an Jiaotong University and Chinese Academy of Sciences.

\section{REFERENCES}

Doupé JP. 2004. Assessment of strategies for measuring $\mathrm{Cl}-36$ in natural samples $[\mathrm{PhD}$ dissertation]. University of Toronto.

Dunkin DB, Fehsenfeld FC, Ferguson EE. 1972. Thermal energy rate constants for the reactions $\mathrm{NO}_{2}^{-}+$ $\mathrm{Cl}_{2} \rightarrow \mathrm{Cl}^{-}{ }_{2}+\mathrm{NO}_{2}, \mathrm{Cl}^{-}{ }_{2}+\mathrm{NO}_{2} \rightarrow \mathrm{Cl}^{-}+\mathrm{NO}_{2} \mathrm{Cl}, \mathrm{SH}^{-}$

$+\mathrm{NO}_{2} \rightarrow \mathrm{NO}^{-}{ }_{2}+\mathrm{SH}, \mathrm{SH}^{-}+\mathrm{Cl}_{2} \rightarrow \mathrm{Cl}^{-}{ }_{2}+\mathrm{SH}$, and $\mathrm{S}^{-}$

$+\mathrm{NO}_{2} \rightarrow \mathrm{NO}^{-}{ }_{2}+\mathrm{S}$. Chemical Physics Letters 15(2): 257-9.
Eliades J, Litherland AE, Kieser WE, Cousins L, Yeb SJ, Zhao X-L. 2009. Cl/S isobar separation using an online reaction cell for ${ }^{36} \mathrm{Cl}$ measurements at low energies. Nuclear Instruments and Methods in Physics Research $B$ : doi:10.1016/j.nimb.2009.10.044

Elmore D, Bhattacharyya MH, Sacco-Gibson N, Peterson DP. 1990. Calcium-41 as a long-term biological tracer for bone resorption. Nuclear Instruments and Methods in Physics Research B 52(3-4):531-5. 
Freeman SPHT, Serfass RE, King JC, Southon JR, Fang Y, Woodhouse LR, Bench GS, McAninch JE. 1995. Biological sample preparation and ${ }^{41} \mathrm{Ca}$ AMS measurement at LLNL. Nuclear Instruments and Methods in Physics Research B 99(1-4):557-61.

Galindo-Uribarri A, Beene JR, Danchev M, Doupé J, Fuentes IB, Gomez del Campo J, Hausladen PA, Juras RC, Liang JF, Litherland AE, Liu Y, Meigs MJ, Mills GD, Mueller PE, Padilla-Rodal E, Pavan J, Sinclair JW, Stracener DW. 2007. Pushing the limits of accelerator mass spectrometry. Nuclear Instruments and Methods in Physics Research B 259(1):123-30.

Gutsev GL. 1993. A theoretical investigation of the electronic and geometric structure of silicon fluorides $\mathrm{SiF} n$ and their anions $\mathrm{SiF}^{-}, n=1-6$. Russian Chemical Bulletin 42(1):36-45.

Kilius LR, Rucklidge JC, Wilson GC, Lee HW, Chang $\mathrm{KH}$, Litherland AE, Kieser WE, Beukens RP, Gorton MP. 1984. Charge ratio mass spectrometry of heavy elements. Nuclear Instruments and Methods in Physics Research B 5(2):185-92.

Kilius LR, Rucklidge JC, Litherland AE. 1987. Accelerator mass spectrometry of ${ }^{129} \mathrm{I}$ at IsoTrace. Nuclear Instruments and Methods in Physics Research B 29(12):72-6.
Kilius LR, Baba N, Garwan MA, Litherland AE, Nadeau M-J, Rucklidge JC, Wilson GC, Zhao X-L. 1990. AMS of heavy ions with small accelerators. Nuclear Instruments and Methods in Physics Research B 52(34):357-65.

Litherland AE, Tomski I, Zhao XL, Cousins L, Doupé JP, Javahery G, Kieser WE. 2007. Isobar separation at very low energy for AMS. Nuclear Instruments and Methods in Physics Research B 259(1):230-5.

Paul M. 1990. Separation of isobars with a gas-filled magnet. Nuclear Instruments and Methods in Physics Research B 52(3-4):315-21.

Raisbeck GM, Yiou F, Bourlès D, Brown E, Deboffle D, Jouhanneau P, Lestringuez J, Zhou ZQ. 1994. The AIMS facility at Gif-sur-Yvette: progress, perturbations and projects. Nuclear Instruments and Methods in Physics Research B 92(1-4):43-6

Tanner SD, Baranov VI, Bandura DM. 2002. Reaction cells and collision cells for ICP-MS: a tutorial review. Spectrochimica Acta B 57(9):1361-452.

Zhao X-L, Eliades J, Liu Q, Kieser WE, Litherland AE, Ye S, Cousins L. 2009. Studies of anions from sputtering III: the ${ }^{41} \mathrm{~K}$ background in ${ }^{41} \mathrm{CaF}_{3}{ }^{-}$measurement by AMS. Nuclear Instruments and Methods in Physics Research B: doi:10.1016/j.nimb.2009.10.038 